\title{
Expression of 14-3-3o in cervical squamous cell carcinomas: Relationship with clinical outcome
}

\author{
RUTH HOLM ${ }^{1}$, TAYEBA ALI ${ }^{1,2}$, DEBBIE H. SVENDSRUD ${ }^{3}$, JAHN M. NESLAND ${ }^{1,2}$, \\ GUNNAR B. KRISTENSEN ${ }^{4,5}$ and HEIDI LYNG ${ }^{3}$ \\ ${ }^{1}$ Division of Pathology, The Norwegian Radium Hospital, Oslo University Hospital; ${ }^{2}$ Faculty Division, \\ The Norwegian Radium Hospital, Medical Faculty, University of Oslo; ${ }^{3}$ Department of Radiation Biology, \\ Institute for Cancer Research, ${ }^{4}$ Division of Obstetrics and Gynaecology and ${ }^{5}$ Department of Medical \\ Informatics, The Norwegian Radium Hospital, Oslo University Hospital, 0310 Oslo, Norway
}

Received March 3, 2009; Accepted April 10, 2009

DOI: 10.3892/or_00000399

\begin{abstract}
B1 complex in the cytoplasm resulting in $\mathrm{G} 2$ arrest. Inactivation and reduced expression of 14-3-3o have been reported in a varity of cancers. In the present study, we investigated the expression of 14-3-3 $\sigma$ in a series of 297 cervical squamous cell carcinoma (SCC) to clarify the prognostic value. Using immunohistochemical methods we found high levels of 14$3-3 \sigma$ protein in cytoplasm of $143(48.1 \%)$, in nucleus of 113 $(38.0 \%)$ and in both cytoplasm and nucleus of 147 (49.5\%) cases, whereas, low levels were present in cytoplasm of 154 $(51.9 \%)$, in nucleus of $184(62.0 \%)$ and in both cytoplasm and nucleus of 150 (50.5\%) cases. Levels of 14-3-3o mRNA measured by reverse-transcription polymerase chain reaction (RT-PCR) and 14-3-3o protein were not significant associated. 14-3-3o expression in cytoplasm, nuclear and cytoplasm/nuclear were not significantly correlated to disease-specific survival or disease-free survival. In conclusion, reduced expression of $14-3-3 \sigma$ protein in the

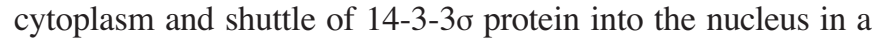
relatively high number of cases indicate that $14-3-3 \sigma$ may be important in the carcinogenesis of cervical SCCs by two different mechanisms; reduction and nuclear translocation of 14-3-3 $\sigma$ protein. Furthermore, the non-significant correlation between expression levels of 14-3-3 $\sigma$ mRNA and protein support a post-transcriptional regulation in cervical SCCs. The protein has no prognostic value in cervical cancers.
\end{abstract}

\section{Introduction}

Cervical carcinoma is the second most common cancer among women worldwide (1). Independent prognostic factors

Correspondence to: Dr Ruth Holm, Division of Pathology, The Norwegian Radium Hospital, Montebello, 0310 Oslo, Norway

E-mail: ruth.holm@radiumhospitalet.no

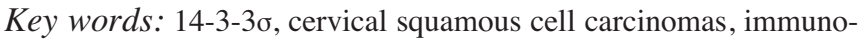
histochemistry include patient age, clinical stage, tumor size, lymph node metastasis and lymph-blood vessel invasion (2-7). These parameters are not sufficient to obtain an exact prediction of prognosis. Therefore, identification of new biological markers may be useful to determine patient outcome.

14-3-3 proteins represent a family of at least seven mammalian isoforms, which are highly conserved acidic proteins, involved in regulating signal transduction pathways, adhesion, apoptosis, differentiation, cellular proliferation and survival $(8,9)$. Of these isoforms, $14-3-3 \sigma$ is restricted to be a human epithelial marker (10). Previous studies have shown that after DNA damage increased expression of 14-3-3o is mediated by $\mathrm{p} 53$ and $\mathrm{p} 21$. The increase of $14-3-3 \sigma$ protein expression results in $\mathrm{G} 2 / \mathrm{M}$ arrest by binding to and sequestering the cdc2-cyclin B1 complexes in the cytoplasm (11). In addition, 14-3-3 $\sigma$ binds to cdk 2 and cdk4 and emerges as a new class of cdk inhibitors (12). These findings indicate that inactivation and low expression of 14-3-30 may be involved in malignant transformation.

Inactivation of 14-3-3 $\sigma$ gene by $\mathrm{CpG}$ methylation and/or reduced expression of 14-3-3 $\sigma$ have been reported in a varity of human cancers, including ovarian $(13,14)$, cervix $(15)$, vulvar $(16,17)$, corpus (18), lung (19), oral (20), liver (21), skin $(22)$, breast $(23,24)$, gastric $(25,26)$, renal $(27)$, testis (27) and colorectal (28). Association of 14-3-3 $\sigma$ with clinical outcome has been found in patients with endometrial carcinoma (18), ovarian carcinoma (14), breast carcinoma (24) and colorectal carcinoma (28). However, the clinical importance of 14-3-3 $\sigma$ in patients with cervical carcinomas has not been studied. Therefore, in the present study, we

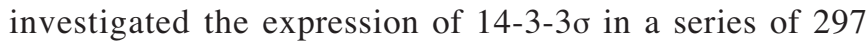
cervical SCC to clarify the prognostic value.

\section{Materials and methods}

Patients and clinical data. Tissue samples from 297 patients with cervical SCCs, FIGO stage I-IV were included in the present study (Table I). The patients were treated at The Norwegian Radium Hospital in the period 1995-2005. The ages of patients range from 26 to 92 years (median 55 years). One hundred and thirteen $(38.0 \%)$ of the patients suffered a 
Table I. 14-3-3o in relation to clinical parameters.

\begin{tabular}{|c|c|c|c|c|c|c|c|c|c|c|}
\hline \multirow[b]{2}{*}{ Variables } & \multirow{2}{*}{$\begin{array}{c}\text { Total } \\
\text { no. }\end{array}$} & \multicolumn{3}{|c|}{ Cytoplasm } & \multicolumn{3}{|c|}{ Nucleus } & \multicolumn{3}{|c|}{ Cytoplasm/nucleus } \\
\hline & & Low & High (\%) & $\mathrm{P}^{\mathrm{a}}$ & Low & High (\%) & $\mathrm{P}^{\mathrm{a}}$ & Low & High (\%) & $\mathrm{P}^{\mathrm{a}}$ \\
\hline Age (years) & & & & 0.687 & & & 0.349 & & & 0.531 \\
\hline$\leq 50$ & 123 & 64 & $59(48)$ & & 76 & $47(38)$ & & 64 & $59(92)$ & \\
\hline $50-70$ & 104 & 51 & $53(51)$ & & 60 & $44(42)$ & & 48 & $56(54)$ & \\
\hline$>70$ & 70 & 39 & $31(44)$ & & 48 & $22(31)$ & & 38 & $32(46)$ & \\
\hline FIGO stage & & & & 0.638 & & & 0.227 & & & 0.569 \\
\hline I & 65 & 37 & $28(43)$ & & 38 & $27(42)$ & & 36 & $29(45)$ & \\
\hline II & 132 & 70 & $62(47)$ & & 88 & $44(33)$ & & 69 & $63(48)$ & \\
\hline III & 74 & 35 & $39(53)$ & & 46 & $28(38)$ & & 33 & $41(55)$ & \\
\hline IV & 26 & 12 & $14(54)$ & & 12 & $14(54)$ & & 12 & $14(54)$ & \\
\hline
\end{tabular}

${ }^{\text {aPearson }} \chi^{2}$; FIGO stage, International Federation of Gynecology and Obstetrics.

relapse and $105(33.4 \%)$ died of cervical carcinoma. Followup for all patients range from 1.4 to 149 months (median 48 months), whereas, follow-up for patients still alive range from 16 to 139 months (median 107 months). Samples from 10 normal cervices (patients who underwent amputation of the cervix for prolaps) were used as normal controls. The study was approved by The Regional Committee for Medical Research Ethics South Norway (S-06381a), The Social and Health Directorate (06/4509 and 06/4417) and The Data Inspectorate (06/01467-3).

Immunostaining method. Immunostaining was performed on sections from formalin-fixed, paraffin-embedded tissue, using the Dako EnVision ${ }^{\mathrm{TM}}+$ System, Peroxidase (DAB) (K4007, Dako Corp., CA, USA) and DakoAutostainer. After microwaving in $10 \mathrm{mM}$ citrate buffer $\mathrm{pH} 6.0$ and treatment with $0.03 \%$ hydrogen peroxide $\left(\mathrm{H}_{2} \mathrm{O}_{2}\right)$ for $5 \mathrm{~min}$ the sections were incubated with monoclonal 14-3-3 $\sigma$ antibody (clone 1433S01, $1: 75,2.7 \mu \mathrm{g} \mathrm{IgG}_{1} / \mathrm{ml}$, NeoMarkers, CA, USA) for $30 \mathrm{~min}$ at room temperature. The primary antibody is highly specific to 14-3-3 $\sigma$ and shows no cross-reaction with other isoforms of 14-3-3 (information from NeoMarkers). The slides were then incubated with peroxidase labeled polymer conjugated to goat anti-mouse for $30 \mathrm{~min}, 3$ '3-diaminobenzidine tetrahydrochloride (DAB) for $10 \mathrm{~min}$ and counterstained with hematoxylin, dehydrated, and mounted in Diatex. In all series normal skin has been included as positive controls, whereas, as negative controls mouse myeloma protein of the same subclass and concentration as mouse anti-14-3-3o were used. Both cytoplasmic and nuclear staining were evaluated as positive. Immunostaining was scored on a 3-tiered scale for both extent of staining (percentage of positive tumor cells 1 , $<10 \% ; 2,10-50 \% ; 3,>50 \%)$ and intensity $(1$, absent/weak; 2 , moderate; 3 , strong). A composite score ranging from 1 to 9 for each section was obtained by multiplying the results of extent and intensity. Based on the staining pattern in normal cervical epithelium 14-3-3o expression in cytoplasm was defined as high when composite scores were 9 , whereas in

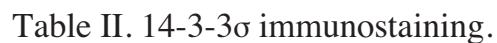

\begin{tabular}{ccccccc}
\hline Score & $\begin{array}{c}\text { Cytoplasm } \\
\mathrm{n}(\%)\end{array}$ & \multicolumn{2}{c}{$\begin{array}{c}\text { Nucleus } \\
\mathrm{n}(\%)\end{array}$} & \multicolumn{2}{c}{$\begin{array}{c}\text { Cytoplasm/nucleus } \\
\mathrm{n}(\%)\end{array}$} \\
\hline 0 & 1 & $(0.3)$ & 184 & $(62.0)$ & 1 & $(0.3)$ \\
1 & 1 & $(0.3)$ & 0 & & 1 & $(0.3)$ \\
2 & 5 & $(1.7)$ & 7 & $(2.4)$ & 5 & $(1.7)$ \\
3 & 24 & $(8.1)$ & 98 & $(33.0)$ & 24 & $(8.1)$ \\
4 & 7 & $(2.4)$ & 0 & & 7 & $(2.4)$ \\
6 & 116 & $(39.1)$ & 6 & $(2.0)$ & 112 & $(37.7)$ \\
9 & 143 & $(48.1)$ & 2 & $(0.7)$ & 147 & $(49.5)$ \\
Total & $297(100.0)$ & 297 & $(100.0)$ & 297 & $(100.0)$ \\
\hline
\end{tabular}

nucleus high expression group includes all the tumors with any staining.

RNA methods. 14-3-3o mRNA levels were assessed by quantitative real-time PCR (qRT PCR) analysis of 91 tumors as described previously (29). Total RNA was isolated from snapfrozen tumor specimens by use of TRIzol reagent (Invitrogen, Carlsbad, CA) followed by precipitation with isopropanol and $5 \mathrm{M}$ lithium chloride. cDNA (10 ng), synthesized from the total RNA by use of Supercript III transcriptase (Invitrogen),

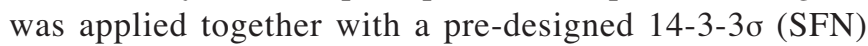
specific TaqMan probe and primer set (Applied Biosystems, Foster City, CA). Each reaction was carried out in triplicate, using the following amplification conditions: one cycle with of $50^{\circ} \mathrm{C}$ in $2 \mathrm{~min}$, one cycle with $95^{\circ} \mathrm{C}$ in 10 min followed by 40 cycles of $95^{\circ} \mathrm{C}$ in $15 \mathrm{sec}$ and $60^{\circ} \mathrm{C}$ in $1 \mathrm{~min}$. The $14-3-3 \sigma$ mRNA level was calculated relative to the endogenous control B2M.

Statistical analyses. The correlation between 14-3-3 $\sigma$ mRNA level and protein expression was investigated with Spearman 

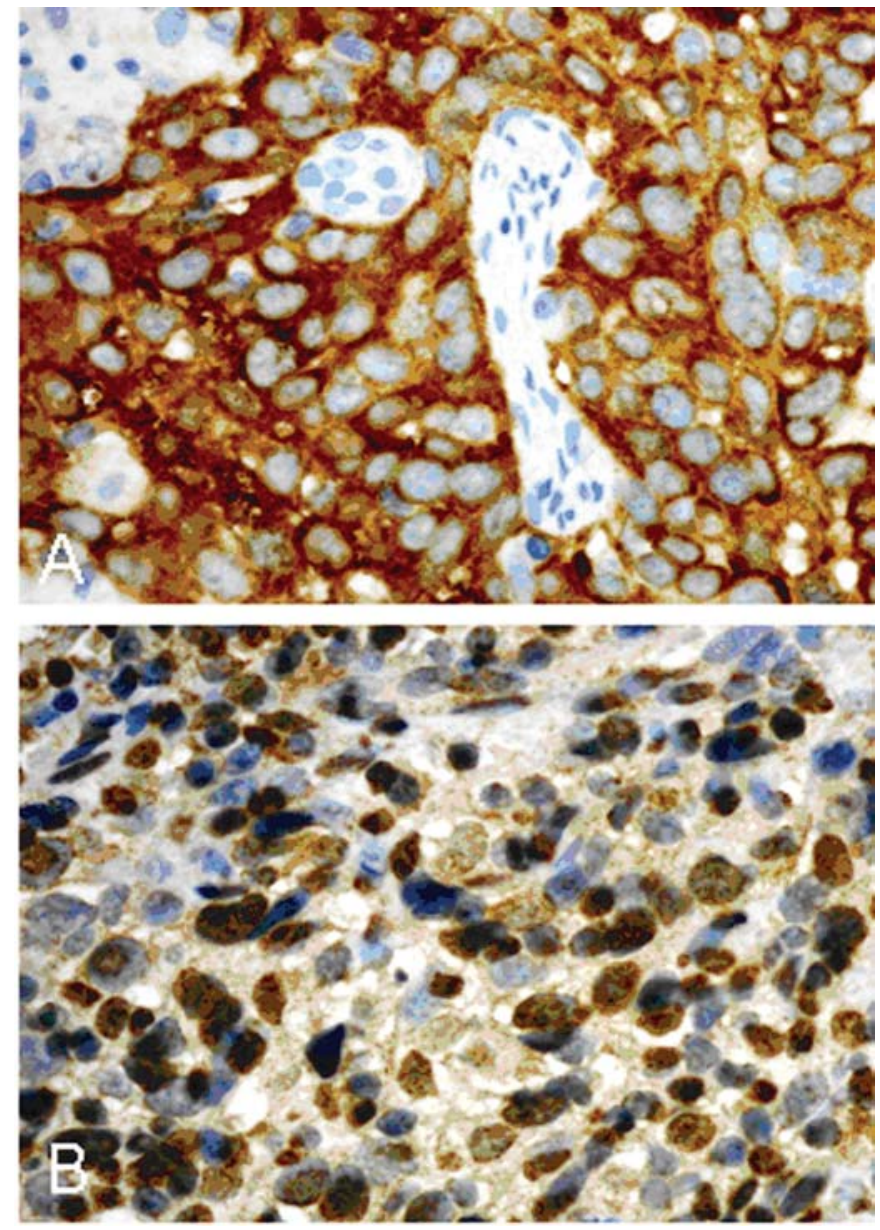

Figure 1. Immunohistochemical staining showing $14-3-3 \sigma$ protein in cytoplasm (A) and nucleus (B).

rank order analysis. The relation between 14-3-3o expression and age or FIGO stage was evaluated by the Person $\chi^{2}$ test. Kaplan and Meier were used to calculate survival curves and categories of 14-3-3 $\sigma$ were compared by the log-rank test. Disease-specific and disease-free survival was defined as the time between diagnosis and death or relapse due to cervical cancer, respectively. For multivariate analysis of survival rate, the Cox proportional hazards regression model with a backward stepwise regression and a $\mathrm{P}=0.05$ in univariate analysis as the inclusion criterion were used. The analysis was performed using the SPSS 15.0 statistical software package (SPSS, Chicago, IL). P $\leq 0.05$ was considered as statistical significance.

\section{Results}

In normal cervical epithelium, high expression of 14-3-3o protein in cytoplasm was found in 10/10 (100\%) cases, whereas, no nuclear staining was seen. Positive staining for 14-3-3o was observed in basal, parabasal, middle and top layers of cervical epithelium. In cervical SCCs, high levels of 14-3-3 $\sigma$ protein was observed in cytoplasm of 143 (48.1\%), in nucleus of $113(38.0 \%)$ and in both cytoplasm and nucleus of $147(49.5 \%)$ cases, whereas, low levels were present in cytoplasm of $154(51.9 \%)$, in nucleus of $184(62.0 \%)$ and in both cytoplasm and nucleus of $150(50.5 \%)$ cases (Table II, Fig. 1). There was no association between 14-3-3o mRNA level and protein expression, regardless of whether the protein level in the cytoplasm, nucleus or both was considered (Fig. 2).

The levels of 14-3-3o were not significantly associated to age and FIGO stage (Table I). In univariate analysis, 14-3-3o expression in cytoplasm, nuclear and cytoplasm/nuclear were not significantly associated to disease-specific survival $(\mathrm{P}=0.705,0.193$ and 0.793 , respectively) and disease-free survival ( $\mathrm{P}=0.519,0.200$ and 0.573 , respectively). Increasing age and FIGO stage were significantly correlated to shorter disease-specific survival ( $\mathrm{P}<0.001$ and $<0.001$, respectively) and disease-free survival ( $\mathrm{P}<0.006$ and $<0.001$, respectively). In multivariate analysis, FIGO stage and age were of independent prognostic significance for disease-specific

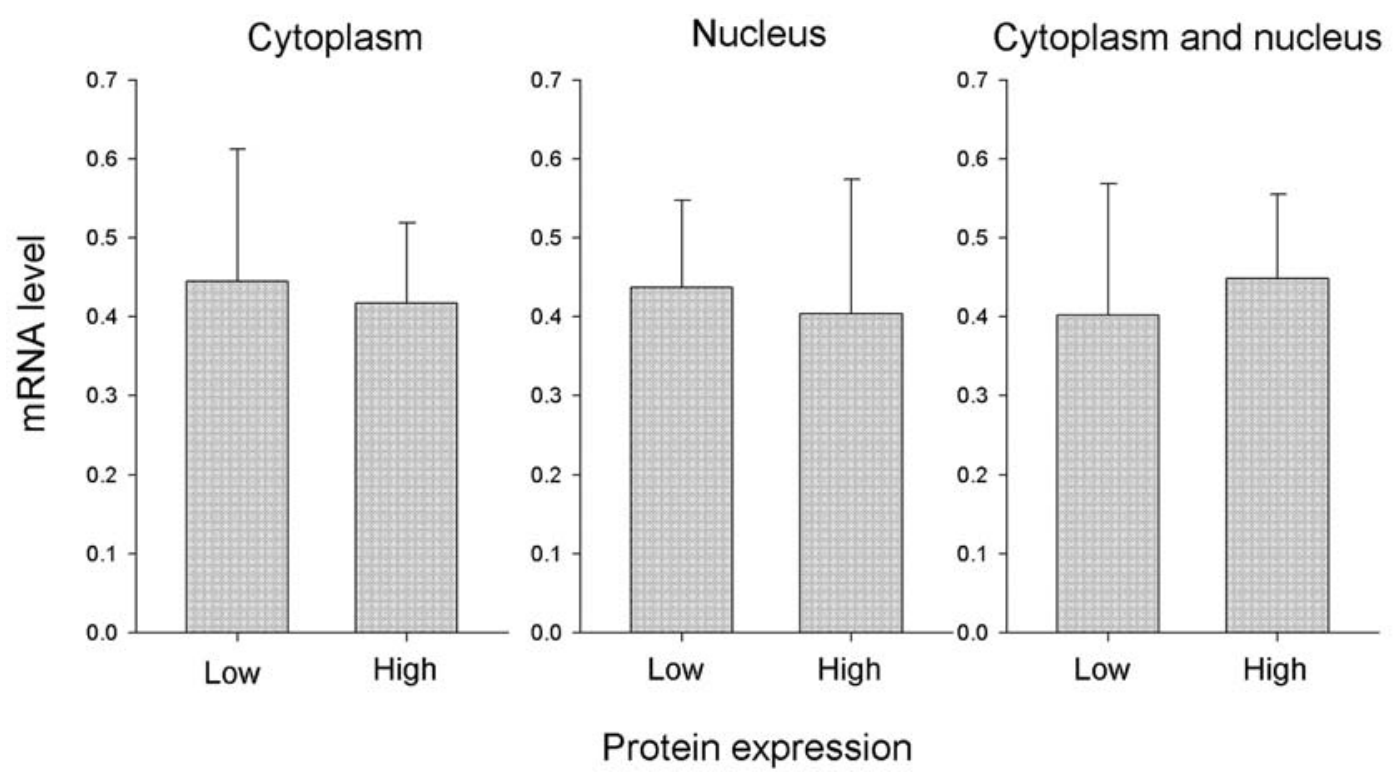

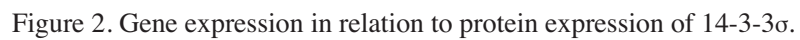


Table III. Multivariate analysis.

\begin{tabular}{|c|c|c|c|c|}
\hline Variables & Grouping & Hazard of risk (HR) & $95 \% \mathrm{Cl}^{\mathrm{a}}$ & P-value ${ }^{b}$ \\
\hline \multicolumn{5}{|c|}{$\begin{array}{l}\text { Disease-specific } \\
\text { survival }\end{array}$} \\
\hline FIGO stage & I vs. II vs. III vs. IV & 2.08 & $1.67-2.59$ & $<0.001$ \\
\hline Age & $<50$ years vs. $50-70$ years vs. $>70$ years & 1.52 & $1.18-1.94$ & 0.001 \\
\hline \multicolumn{5}{|l|}{$\begin{array}{l}\text { Disease-free } \\
\text { survival }\end{array}$} \\
\hline FIGO stage & I vs. II vs. III vs. IV & 2.03 & $1.64-2.51$ & $<0.001$ \\
\hline
\end{tabular}

survival, whereas only FIGO stage was of independent prognostic significance for disease-free survival (Table III).

\section{Discussion}

Reduced expression of 14-3-3o protein has been documented in ovarian $(13,14)$, corpus $(18)$, vulvar $(17)$, lung $(19)$, oral (20), liver (21), skin (22) and breast carcinomas (24). Furthermore, Mhawech et al (15) identified low level of 143-3o protein in 3/9 $(33 \%)$ cervical SSCs, whereas, Sano et al (30) did not find low level of 14-3-30 protein in any of the 29 cervical SSCs tested. In the present study we detected low level of $14-3-3 \sigma$ in about $50 \%$ of cervical SSCs when comparing with normal cervical squamous epithelium. These conflicting results may be explained by the small number of cases included in the previous works $(15,30)$, the use of different 14-3-3 $\sigma$ antibodies and immunohistochemical staining methods and the differences in scoring of the immunohistochemical staining. The low 14-3-3 $\sigma$ protein level in a relative high number of cervical SSC and the finding of no association between 14-3-3 $\sigma$ protein expression and FIGO stage, suggested that loss of 14-3-3o protein expression may occur as a relatively early event in cervical tumorigenesis.

In normal cervical epithelium high expression of 14-3-3o protein in cytoplasm was found in all 10 cases, whereas, no nuclear staining was seen. This is in accordance with a

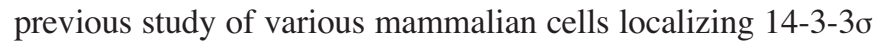
mainly in the cytoplasm and only low levels in the nucleus (31). The high expression of cytoplasmic 14-3-3o in normal cervical epithelium may contribute to $\mathrm{G} 2 / \mathrm{M}$ arrest by binding to and sequestering the cdc2-cyclin B1 in the cytoplasm (11). A different subcellular distribution of $14-3-3 \sigma$ protein was identified in cervical SCCs where high 14-3-3o expression was found in the cytoplasm and nucleus in 48 and $38 \%$ of the cases, respectively. The shuttle of 14-3-3 $\sigma$ into the nucleus of

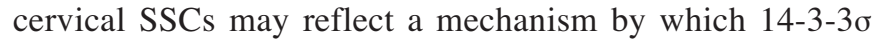
reduces the capacity to keep the cdc2-cyclin $\mathrm{B} 1$ complex in the cytoplasm resulting in failure of $\mathrm{G} 2 / \mathrm{M}$ arrest and entering cells into mitosis. Therefore, $14-3-3 \sigma$ protein nuclear localization may be important in the carcinogenesis of cervical SCCs.
No previous studies are available on the prognostic significance of 14-3-3 $\sigma$ protein expression in cervical SCC. We did not find a statistical association between 14-3-3 $\sigma$ protein expression and disease-specific survival. This is in accordance with the data in breast carcinomas (24) and vulvar carcinomas (17). Previously, Akahira et al (14) have reported that in univariate analysis negative 14-3-30 immunoreactive ovarian carcinomas had a significantly poorer overall survival rates than positive cases. However, in multivariate analysis, 14-3-3 $\sigma$ protein expression turned out not to be an independent prognostic marker. In contrast to these studies, Ito et al (18)

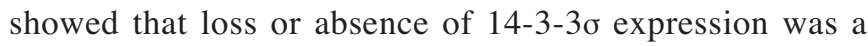
statistically independent risk factor in overall survival in patients with early-stage endometrial cancer, whereas, Perathoner et al (28) identified that 14-3-3o overexpression was associated with significantly decreased survival time in multivariate analysis. Considering these studies together, it seems that 14-3-3o play different role in cancers from different human organs.

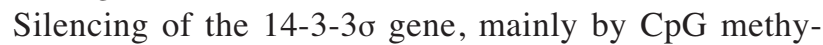
lation, occurs in numerous solid tumor types (9). However, 14-3-3 $\sigma$ expression may also be regulated at the posttranscriptional level. The non-significant correlation between expression levels of 14-3-3 $\sigma$ mRNA and protein in our study support a post-transcriptional regulation in cervical SCCs. This is in line with the results in cervical adeno/adenosquamous carcinomas (30), vulvar squamous cell carcinomas (17) and colon cancer cell lines (28) where the expression of 14-3-3 $\sigma$ mRNA and protein were not significantly associated. Different mechanisms have been indicated for the regulation at the post-transcriptional level. Audic and Hartley (32) have reported that there may be modifications of mRNA stability and/or translation efficiency. In addition, Urano et al (33) showed that Efp, a RING-finger-dependent ubiquitin ligase, targets proteolysis of $14-3-3 \sigma$ protein, indicating downregulation of 14-3-3 $\sigma$ protein through a proteasome-dependent mechanism.

In conclusion, reduced expression of $14-3-3 \sigma$ protein in the cytoplasm of $51.9 \%$ of the cases and shuttle of $14-3-3 \sigma$ protein into the nucleus of $38 \%$ of the cases indicate that 14-3-3 $\sigma$ may be important in the carcinogenesis of cervical SCCs. Furthermore, the non-significant correlation between 
expression levels of 14-3-3 $\sigma$ mRNA and protein supports a post-transcriptional regulation in cervical SCCs. No significant correlation was seen between cytoplasmic and/or nuclear 14-3-3o protein and survival.

\section{Acknowledgements}

We thank Ellen Hellesylt and Inger Liv Håseth for excellent technical support. This project was supported by grants from The University of Oslo and The Norwegian Cancer Society. Tayyeba Ali has a scholarship from the University of Oslo.

\section{References}

1. Globocan 2000: Cancer incidence, mortality and prevalence worldwide. In: IARC Cancer Base No. 5 (Version 1.0). IARCPress, Lyon, 2001

2. Gasinska A, Urbanski K, Adamczyk A, Pudelek J, Lind BK and Brahme A: Prognostic significance of intratumour microvessel density and haemoglobin level in carcinoma of the uterine cervix. Acta Oncol 41: 437-443, 2002

3. Van Bommel PF, van Lindert AC, Kock HC, Leers WH and Neijt JP: A review of prognostic factors in early-stage carcinoma of the cervix (FIGO I B and II A) and implications for treatment strategy. Eur J Obstet Gynecol Reprod Biol 26: 69-84, 1987.

4. Kawagoe T, Kashimura M, Matsuura Y, Sugihara K, Toki N and Aoki T: Clinical significance of tumor size in stage IB and II carcinoma of the uterine cervix. Int J Gynecol Cancer 9: 421-426, 1999.

5. Waggoner SE: Cervical cancer. Lancet 361: 2217-2225, 2003.

6. Creasman WT and Kohler MF: Is lymph vascular space involvement an independent prognostic factor in early cervical cancer? Gynecol Oncol 92: 525-529, 2004.

7. Rutledge FN, Mitchell MF, Munsell M, Bass S, McGuffee V and Atkinson EN: Youth as a prognostic factor in carcinoma of the cervix: a matched analysis. Gynecol Oncol 44: 123-130, 1992.

8. Muslin AJ, Tanner JW, Allen PM and Shaw AS: Interaction of 14-3-3 with signaling proteins is mediated by the recognition of phosphoserine. Cell 84: 889-897, 1996.

9. Mhawech P: 14-3-3 proteins - an update. Cell Res 15: 228-236, 2005.

10. Prasad GL, Valverius EM, McDuffie E and Cooper HL: Complementary DNA cloning of a novel epithelial cell marker protein, HME1, that may be down-regulated in neoplastic mammary cells. Cell Growth Differ 3: 507-513, 1992.

11. Chan TA, Hermeking H, Lengauer C, Kinzler KW and Vogelstein B: 14-3-3Sigma is required to prevent mitotic catastrophe after DNA damage. Nature 401: 616-620, 1999.

12. Laronga C, Yang HY, Neal C and Lee MH: Association of the cyclin-dependent kinases and 14-3-3 sigma negatively regulates cell cycle progression. J Biol Chem 275: 23106-23112, 2000.

13. Kaneuchi M, Sasaki M, Tanaka Y, Shiina H, Verma M, Ebina Y, Nomura E, Yamamoto R, Sakuragi N and Dahiya R: Expression and methylation status of 14-3-3 sigma gene can characterize the different histological features of ovarian cancer. Biochem Biophys Res Commun 316: 1156-1162, 2004.

14. Akahira J, Sugihashi Y, Suzuki T, Ito K, Niikura H, Moriya T, Nitta M, Okamura H, Inoue $\mathrm{S}$, Sasano $\mathrm{H}$, Okamura $\mathrm{K}$ and Yaegashi N: Decreased expression of 14-3-3 sigma is associated with advanced disease in human epithelial ovarian cancer: its correlation with aberrant DNA methylation. Clin Cancer Res 10: 2687-2693, 2004.

15. Mhawech P, Greloz V, Assaly M and Herrmann F: Immunohistochemical expression of 14-3-3 sigma protein in human urological and gynecological tumors using a multi-tumor microarray analysis. Pathol Int 55: 77-82, 2005.

16. Gasco M, Sullivan A, Repellin C, Brooks L, Farrell PJ, Tidy JA, Dunne B, Gusterson B, Evans DJ and Crook T: Coincident inactivation of 14-3-3 sigma and p16INK4a is an early event in vulval squamous neoplasia. Oncogene 21: 1876-1881, 2002.

17. Wang Z, Trope CG, Suo Z, Troen G, Yang G, Nesland JM and Holm R: The clinicopathological and prognostic impact of 14-3-3 sigma expression on vulvar squamous cell carcinomas. BMC Cancer 8: 308, 2008.
18. Ito K, Suzuki T, Akahira J, Sakuma M, Saitou S, Okamoto S Niikura H, Okamura K, Yaegashi N, Sasano H and Inoue S: 14-3-3sigma in endometrial cancer - a possible prognostic marker in early-stage cancer. Clin Cancer Res 11: 7384-7391, 2005.

19. Osada H, Tatematsu Y, Yatabe Y, Nakagawa T, Konishi H, Harano T, Tezel E, Takada $M$ and Takahashi T: Frequent and histological type-specific inactivation of 14-3-3sigma in human lung cancers. Oncogene 21: 2418-2424, 2002.

20. Gasco M, Bell AK, Heath V, Sullivan A, Smith P, Hiller L, Yulug I, Numico G, Merlano M, Farrell PJ, Tavassoli M, Gusterson B and Crook T: Epigenetic inactivation of 14-3-3 sigma in oral carcinoma: association with p16(INK4a) silencing and human papillomavirus negativity. Cancer Res 62: 2072-2076, 2002.

21. Iwata N, Yamamoto H, Sasaki S, Itoh F, Suzuki H, Kikuchi T, Kaneto H, Iku S, Ozeki I, Karino Y, Satoh T, Toyota J, Satoh M, Endo T and Imai K: Frequent hypermethylation of $\mathrm{CpG}$ islands and loss of expression of the 14-3-3 sigma gene in human hepatocellular carcinoma. Oncogene 19: 5298-5302, 2000.

22. Lodygin D, Yazdi AS, Sander CA, Herzinger T and Hermeking H: Analysis of 14-3-3sigma expression in hyperproliferative skin diseases reveals selective loss associated with CpG-methylation in basal cell carcinoma. Oncogene 22: 5519-5524, 2003.

23. Ferguson AT, Evron E, Umbricht CB, Pandita TK, Chan TA, Hermeking H, Marks JR, Lambers AR, Futreal PA, Stampfer MR and Sukumar S: High frequency of hypermethylation at the 14-3-3 sigma locus leads to gene silencing in breast cancer. Proc Natl Acad Sci USA 97: 6049-6054, 2000.

24. Simpson PT, Gale T, Reis-Filho JS, Jones C, Parry S, Steele D, Cossu A, Budroni M, Palmieri G and Lakhani SR: Distribution and significance of 14-3-3sigma, a novel myoepithelial marker, in normal, benign, and malignant breast tissue. J Pathol 202: 274-285, 2004.

25. Suzuki H, Itoh F, Toyota M, Kikuchi T, Kakiuchi H and Imai K: Inactivation of the 14-3-3 sigma gene is associated with 5' CpG island hypermethylation in human cancers. Cancer Res 60: 4353-4357, 2000.

26. Tanaka K, Hatada T, Kobayashi M, Mohri Y, Tonouchi H, Miki C, Nobori T and Kusunoki M: The clinical implication of 14-3-3 sigma expression in primary gastrointestinal malignancy. Int J Oncol 25: 1591-1597, 2004.

27. Mhawech P, Benz A, Cerato C, Greloz V, Assaly M, Desmond JC, Koeffler HP, Lodygin D, Hermeking H, Herrmann F and Schwaller J: Down-regulation of 14-3-3sigma in ovary, prostate and endometrial carcinomas is associated with CpG island methylation. Mod Pathol 18: 340-348, 2005.

28. Perathoner A, Pirkebner D, Brandacher G, Spizzo G, Stadlmann S, Obrist P, Margreiter R and Amberger A: 14-3-3sigma expression is an independent prognostic parameter for poor survival in colorectal carcinoma patients. Clin Cancer Res 11: 3274-3279, 2005.

29. Lyng H, Brovig RS, Svendsrud DH, Holm R, Kaalhus O, Knutstad K, Oksefjell H, Sundfor K, Kristensen GB and Stokke T: Gene expressions and copy numbers associated with metastatic phenotypes of uterine cervical cancer. BMC Genomics 7: 268, 2006

30. Sano T, Shimooka H, Weixa P, Segawa A, Jian Z, Motegi A, Nakayama H, Oyama T and Nakajima T: Immunohistochemical expression of 14-3-3 sigma protein in various histological sub-types of uterine cervical cancers. Pathol Int 54: 743-750, 2004.

31. Van Hemert MJ, Niemantsverdriet M, Schmidt T, Backendorf C and Spaink HP: Isoform-specific differences in rapid nucleocytoplasmic shuttling cause distinct subcellular distributions of 14-3-3 sigma and 14-3-3 zeta. J Cell Sci 117: 1411-1420, 2004.

32. Audic Y and Hartley RS: Post-transcriptional regulation in cancer. Biol Cell 96: 479-498, 2004.

33. Urano T, Saito T, Tsukui T, Fujita M, Hosoi T, Muramatsu M, Ouchi $\mathrm{Y}$ and Inoue S: Efp targets 14-3-3 sigma for proteolysis and promotes breast tumour growth. Nature 417: 871-875, 2002. 